\title{
Long-term fate of the coronary arteries after the arterial switch operation in newborns with transposition of the great arteries
}

\author{
D Bonnet, P Bonhoeffer, J-F Piéchaud, Y Aggoun, D Sidi, C Planché, J Kachaner
}

\begin{abstract}
Objective-Concern continues to be expressed about the long-term impact of coronary artery translocation after the arterial switch operation for transposition of the great arteries. This study was conducted to determine the prevalence of obstructions of the translocated coronary arteries by the use of selective coronary artery angiography.
\end{abstract}

Methods and results -64 children (mean age 7.6 (SD) 1.5 years) who had survived an arterial switch operation underwent evaluation. They had been operated on by one surgeon and they were followed up by a single hospital. Selective coronary artery angiography was possible in $\mathbf{5 8}$ patients. Five patients showed occlusion or stenosis of a coronary artery: one occlusion and two stenoses of the left coronary trunk, two occlusions of the circumflex artery. The prevalence of late coronary artery complications was $7 \cdot 8$ (SD) $6.6 \%(95 \%$ CI 1.2 to $-14 \cdot 4 \%)$. The three patients with occlusion of one coronary artery had perioperative ischaemic complications, with associated electrocardiogram evidence of ischaemia and left ventricular dysfunction with mitral valve insufficiency. Both patients with stenosis of the left main coronary artery trunk did not have any evidence of an anomaly before catheterisation.

Conclusions-The prevalence of the late coronary artery complications after an arterial switch operation was low in this series. This accords with the view that the arterial switch operation remains the preferred treatment for such patients. Screening for late coronary artery patency should be done by using selective coronary artery angiography, because even patients who remain symptom free can have coronary artery anomalies.

(Heart 1996;76:274-279)

Keywords: transposition of the great arteries; coronary artery; switch operation

During the past decade, the arterial switch operation has been increasingly used to correct transposition of the great arteries. ${ }^{1-5}$ The most common late complications for survivors are supravalvar pulmonary stenosis ${ }^{6}$ and neoaortic valve dysfunction. ${ }^{7}$ However, concern contin- ues about the long-term impact of coronary artery translocation. ${ }^{8}$

We have reported our encouraging early and midterm results after the arterial switch operation in the first 50 patients. ${ }^{2} \mathrm{~A}$ few perioperative deaths, however, continue to occur and these are related to coronary artery mobilisation..$^{5910} \mathrm{In}$ addition, late deaths seem to be rare after the arterial switch operation, and in most reported cases the immediate cause of the death was myocardial infarction or severe ventricular dysfunction resulting from stenosis of one or both of the main coronary arteries. ${ }^{1112}$

Various techniques have been used to investigate the long-term outcome of coronary translocation. However, the search for myocardial perfusion anomalies by nuclear scanning is often biased by myocardial damage during cardiopulmonary bypass ${ }^{1314}$ and angiographic imaging of the coronary arteries by aortic root injection may not provide detailed information on coronary artery anatomy.

We report our findings when selective coronary artery angiography was performed 7-8 years after an arterial switch operation.

\section{Patients and methods}

PATIENTS

We selected 78 consecutive newborns for a prospective study with annual detailed follow up. They had survived an arterial switch operation for transposition of the great arteries, had been followed up by the Hôpital NeckerEnfants Malades, and had been operated on by one surgeon (C Planché, Marie Lannelongue Hospital, France) between April 1984 and September 1988. Certain aspects of the study have been reported elsewhere, as has the surgical procedure. ${ }^{415}$ Coronary artery evaluation was performed between September 1991 and June 1995. We obtained the informed consent of the parents of each patient.

Seventy four patients had simple transposition of the great arteries and four patients had transposition of the great arteries associated with a large ventricular septal defect. The mean (SD) age at operation was 8.6 (4.2) days (range 1 to 24 days). The mean (SD) weight was $3.4(0.4) \mathrm{kg}$ (range 2.3 to $4.4 \mathrm{~kg}$ ). All the patients with simple transposition of the great arteries, had balloon atrial septostomy. We did not determine how the coronary artery anatomy was investigated before operation. Two patients died during follow up: one of acute myocardial infarction five weeks after 
Table 1 Classification of pattern of coronary arteries in 64 children after arterial switch operation for transposition of the great arteries

\begin{tabular}{|c|c|c|}
\hline Planche's classification ${ }^{\prime 5}$ & $\begin{array}{l}\text { Yacoub's } \\
\text { classification }^{16}\end{array}$ & $\begin{array}{l}\text { Patients } \\
\text { (no. }(\%))\end{array}$ \\
\hline \multirow{3}{*}{$\begin{array}{l}\text { Two ostia from posterior-facing sinuses with } \\
\text { right and left coronary arteries following } \\
\text { a normal course (type I) } \\
\text { One or two ostia from one or two posterior- } \\
\text { facing sinuses but with one or both arteries } \\
\text { coursing between the great vessels (type II) }\end{array}$} & A & $42(65 \cdot 6 \%)$ \\
\hline & B & $1(1 \cdot 5 \%)$ \\
\hline & $\mathrm{C}$ & $1(1 \cdot 5 \%)$ \\
\hline \multirow{2}{*}{$\begin{array}{l}\text { One or two ostia arising from one or two } \\
\text { posterior-facing sinuses, with one or two } \\
\text { coronary arteries looping around } \\
\text { the great vessels (type III) }\end{array}$} & $\mathrm{D}$ & $12(18 \cdot 7 \%)$ \\
\hline & E & $8(12.5 \%)$ \\
\hline
\end{tabular}

surgery and one of severe pulmonary vascular disease. Eight patients were lost to follow up and four parents refused to participate in the
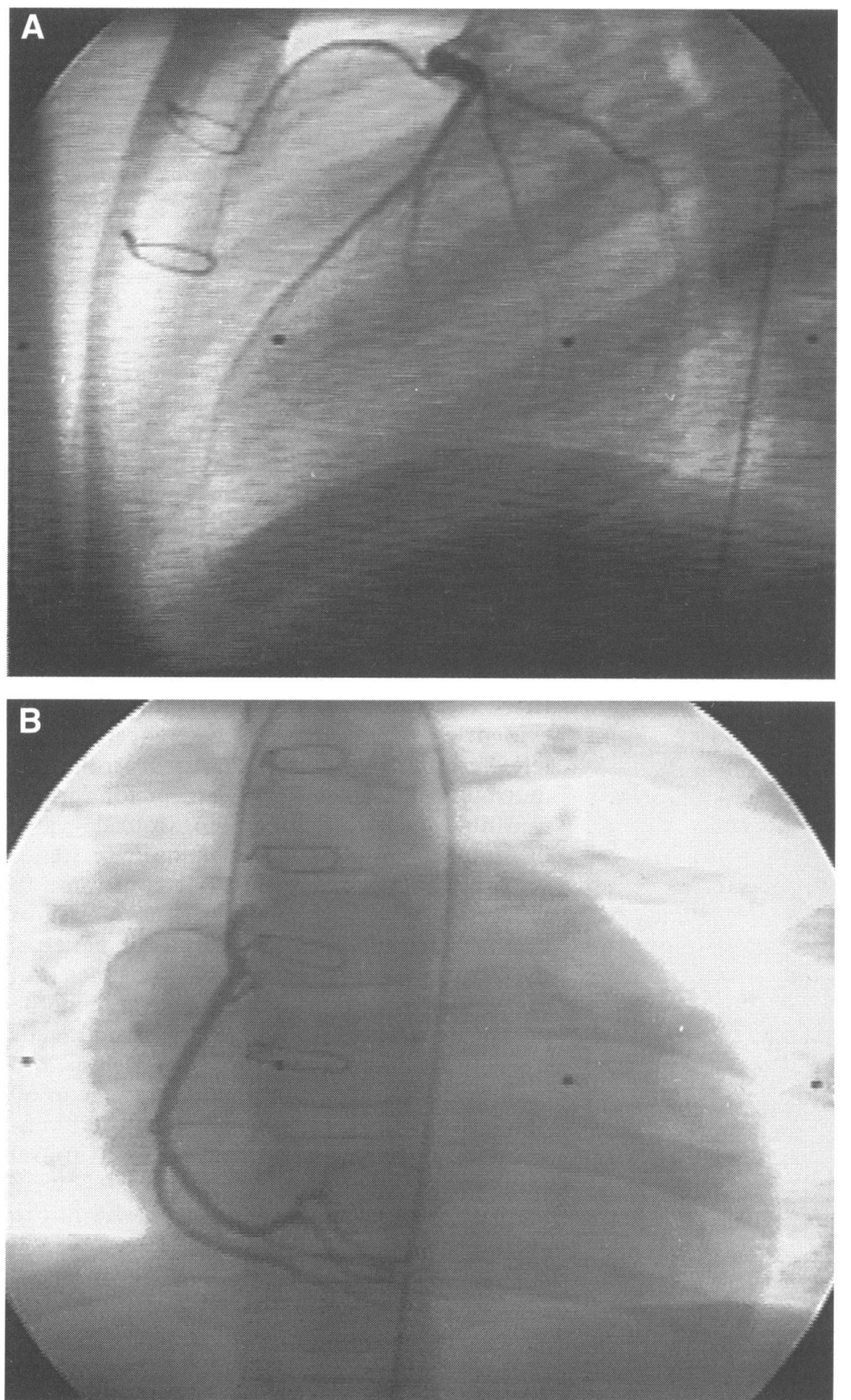

Figure 1 Normal coronary arteries in a type I pattern (Planche's classification), type A pattern (Yacoub's classification). (A) Left coronary artery in lateral view. (B) Right coronary artery in lateral view in the same patient. study. Finally, 64 of the 78 patients who met the eligibility requirements were included in this study.

\section{FUNCTIONAL STATUS}

Patient evaluation included perioperative history, clinical examination, resting 12 lead electrocardiogram (ECG), echocardiogram, and exercise testing. The following perioperative events were noted: (a) peroperative ischaemic events related to coronary artery translocation, (b) early re-intervention because of ischaemic complications, (c) myocardial ischaemia or infarction, $(d)$ left ventricular failure requiring prolonged inotropic support. Clinical evaluation included identification of cardiac failure and chest pain and a complete clinical examination. Echocardiographic studies were used to evaluate left ventricular function and contractility, reduction of segmental wall motion, hyperechogenicity of a papillary muscle of the mitral valve, and mitral valve insufficiency. Treadmill exercise testing was performed according to a modified Bruce protocol with 12 lead ECG monitoring. All ECGs obtained before exercise, at each stage of exercise, and during recovery were reviewed by one of us.

\section{CORONARY ARTERY ANGIOGRAPHY}

TECHNIQUE

Catheterisation was undertaken under local anesthaesia by the femoral arterial approach. Patients were heparinised with 100 units $/ \mathrm{kg}$ of heparin. Selective injection into the coronary ostia was attempted in all patients. In the early part of the study we used right and left coronary catheters $(5 \mathrm{~F}$, Judkins $3.5 \mathrm{~cm}$ and $2.5 \mathrm{~cm}$, (Cordis, Cook)). Because both newly implanted coronary ostia were in an anterior position, we stopped using the left coronary catheter. Selective coronary angiography is now performed exclusively with right coronary catheters (4 and 5F (Cordis, Miami, USA; Cook, Bjaeverfkov, Denmark)) with various curvatures (Judkins: $1 \cdot 5,2,2 \cdot 5,3 \cdot 5,4$ ). The two smallest sizes were made especially for this study (Cordis, Viry-Chatillon, France).

The coronary orifice was searched for in the lateral view, by positioning the distal part of the catheter anteriorly on the aortic wall. Small manual test injections of contrast medium (Omnipaque 300, Nycomed, Oslo, Norway) were performed in order to localise the coronary ostia. After the coronary orifice was entered, coronary angiography was performed by manual injection. Particular attention was paid to the opacification of the coronary orifice and to regurgitation of contrast medium into the aortic root.

Angiograms were performed in the lateral view. In addition, at least one other angiogram was obtained-in right anterior oblique $\left(20^{\circ}\right)$ view for the coronary artery arising from the left side of the neoaortic root and in left anterior oblique $\left(20^{\circ}\right)$ view for the coronary artery arising from the right side. When a coronary abnormality was suspected, we performed an aortic root injection in the projection where the abnormal coronary button could best be 


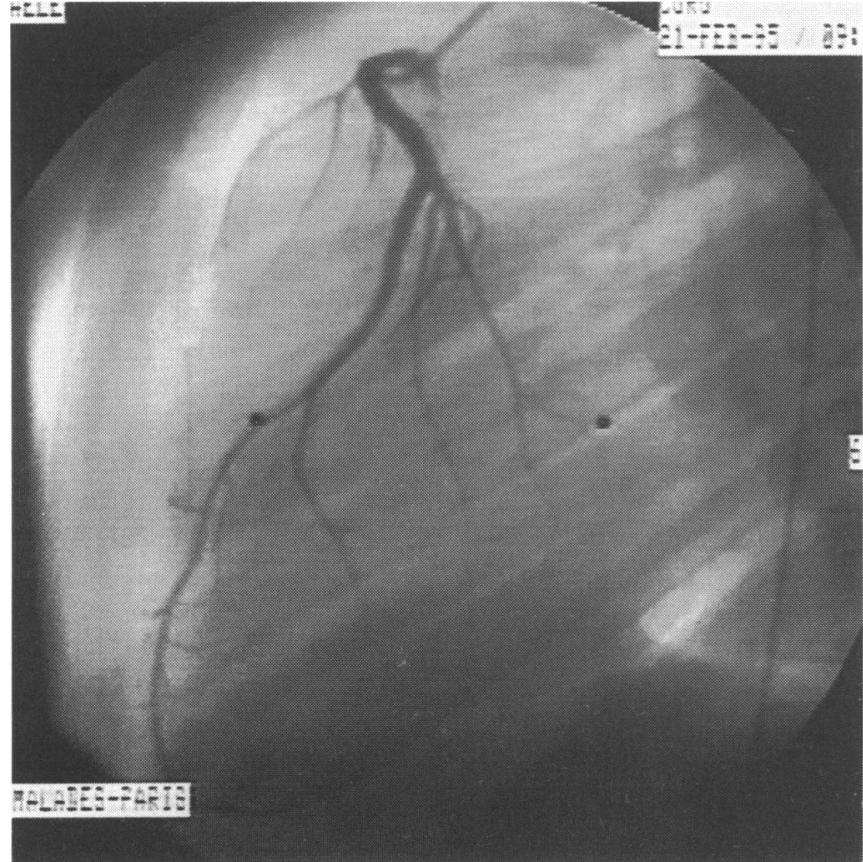

$A$

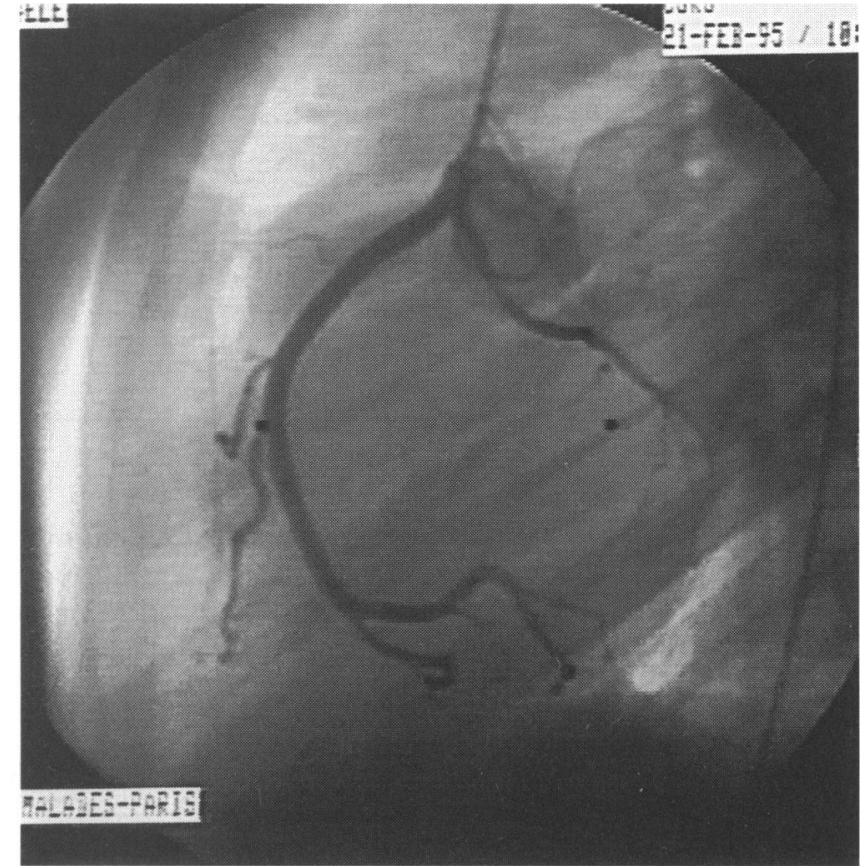

$B$

Figure 2 Normal coronary arteries in a type III pattern (Planché's classification), type D pattern (Yacoub's classification). (A) Left anterior descending artery arising from one sinus. (B) Right coronary artery and left circumflex artery arising from the other sinus. The left circumflex artery loops around the aorta.

distinguished from opacification of the aorta. We classified the coronary artery patterns as described by Serraf et $a l^{15}$ and Yacoub and Radley-Smith ${ }^{16}$ (table 1).

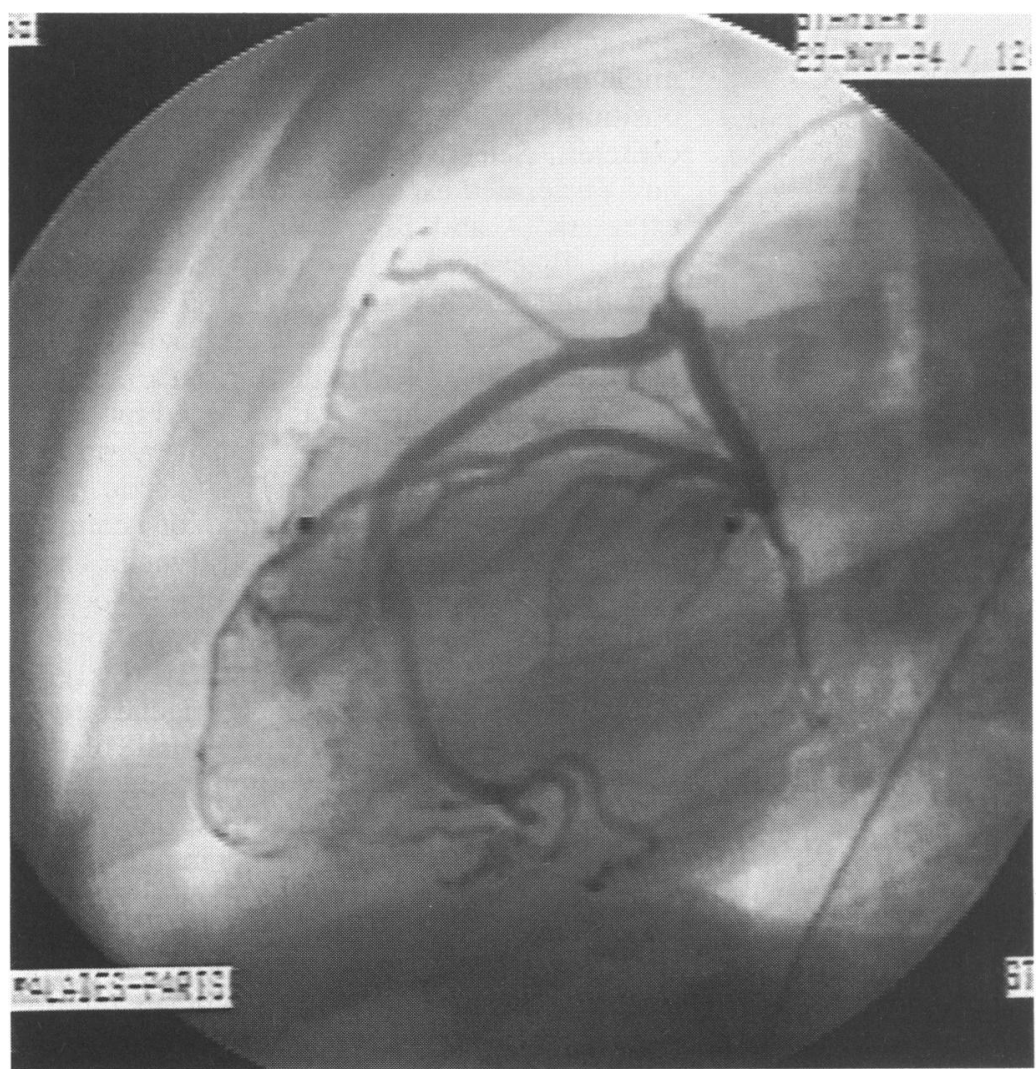

Figure 3 Normal single coronary artery arising from the right ostium. Note that the single coronary artery divides into a right coronary artery and a common trunk looping around the aorta and then dividing into the left anterior descending coronary artery and the circumflex coronary artery.

\section{Results}

FUNCTIONAL STATUS

The mean (SD) age at inclusion was $7.6(1.5)$ years, ranging from 4 to 11 years. The mean (SD) weight at catheterisation was $24.5(5.3)$ $\mathrm{kg}$, ranging from 15 to $43 \mathrm{~kg}$. All patients were in New York Heart Association class I without medication. None had chest pain.

Twenty two patients $(34.4 \%)$ had perioperative complications potentially related to myocardial ischaemia: peroperative coronary artery complications $(n=8)$, early reintervention for coronary artery repositioning $(\mathbf{n}=1)$, myocardial infarction $(\mathbf{n}=2), \mathrm{ECG}$ evidence of myocardial ischaemia $(n=16)$, left ventricular failure requiring prolonged inotropic support $(n=6)$. Except for various murmurs related either to mitral valve insufficiency or supravalvar pulmonary stenosis clinical examination did not contribute to the evaluation. All patients had normal sinus rhythm on the resting ECG. In four patients, the resting ECG showed ST-T changes and two patients had abnormal $Q$ waves, in the posterior leads in one and in the lateral leads in the other. Left ventricular dimensions and shortening were within the normal range in 60 patients $(93 \cdot 6 \%)$. Four patients had left ventricular dysfunction associated with mitral valve insufficiency. Exercise tests were technically possible in 49 patients who ran to "exhaustion". In six children, heart rate did not increase significantly $(<80 \%$ maximal heart rate for age) during exercise and the test was judged to be not suitable for interpretation. Three of the remaining 43 patients had ECG evidence of ischaemia, two during recovery and one during exercise. All patients remained symptom free and none had evidence of ectopic activity. 
Table 2 Clinical course and non-invasive findings in patients with coronary artery obstruction

\begin{tabular}{|c|c|c|c|c|c|c|c|}
\hline Patients & $\begin{array}{l}\text { Age at } C A \\
\text { angiography } \\
\text { (yr) }\end{array}$ & $C A$ type & $\begin{array}{l}\text { Perioperative } \\
\text { coronary } \\
\text { complication }\end{array}$ & Rest ECG & $\begin{array}{l}\text { Exercise } \\
\text { ECG }\end{array}$ & $\begin{array}{l}\text { Echographic } \\
\text { anomaly }\end{array}$ & $C A$ anomaly \\
\hline 1 & $9 \cdot 4$ & I (A)† & + & ST-T anomaly & NS & + & \multirow{5}{*}{$\begin{array}{l}\text { Occlusion of } \\
\text { the MLCA } \\
\text { Stenosis of } \\
\text { the MLCA } \\
\text { Stenosis of } \\
\text { the MLCA } \\
\text { Occlusion of } \\
\text { the Cx } \\
\text { Occlusion of } \\
\text { the Cx }\end{array}$} \\
\hline 2 & $6 \cdot 9$ & III (D) & - & Normal & Negative & - & \\
\hline 3 & $5 \cdot 1$ & III (D) & - & Normal & Negative & - & \\
\hline 4 & $4 \cdot 7$ & I (A) & + & ST-T anomaly & Negative & + & \\
\hline 5 & 8 & I (A) & + & Q waves & NS & + & \\
\hline
\end{tabular}

CA, coronary artery; CX, circumflex artery; ECG, electrocardiogram; MLCA, main left coronary artery.

$\star$ Coronary artery patterns are given in table 1 .

tThe letter in parentheses corresponds to Yacoub's classification

Table 3 Relations between functional status and findings at coronary artery angiography

\begin{tabular}{|c|c|c|c|c|c|c|c|c|c|c|}
\hline & \multicolumn{2}{|c|}{$\begin{array}{l}\text { Perioperative } \\
\text { coronary } \\
\text { complication }\end{array}$} & \multicolumn{2}{|c|}{$\begin{array}{l}\text { Rest ECG } \\
\text { anomaly }\end{array}$} & \multicolumn{2}{|c|}{$\begin{array}{l}\text { Echocardiogram } \\
\text { anomaly }\end{array}$} & \multicolumn{2}{|c|}{$\begin{array}{l}\text { Rest ECG and } \\
\text { echocardiogram } \\
\text { anomalies }\end{array}$} & \multicolumn{2}{|c|}{$\begin{array}{l}\text { Exercise ECG } \\
\text { anomaly }^{\star}\end{array}$} \\
\hline & + & - & + & - & + & - & + & - & + & - \\
\hline $\begin{array}{l}\text { Normal CA angiography } \\
\text { Coronary obstruction }\end{array}$ & $\begin{array}{r}19 \\
3\end{array}$ & $\begin{array}{r}40 \\
2\end{array}$ & $\begin{array}{l}3 \\
3\end{array}$ & $\begin{array}{r}56 \\
2\end{array}$ & $\begin{array}{l}1 \\
3\end{array}$ & $\begin{array}{r}58 \\
2\end{array}$ & $\begin{array}{l}0 \\
3\end{array}$ & $\begin{array}{r}59 \\
2\end{array}$ & $\begin{array}{l}3 \\
0\end{array}$ & $\begin{array}{r}37 \\
3\end{array}$ \\
\hline
\end{tabular}

CA, coronary artery.

$\star 43$ patients had an exercise ECG that was suitable for interpretation.

CORONARY ARTERY ANGIOGRAPHY

Selective coronary angiography could be performed through the two ostia in 58 children. In six patients, one or both ostia could not be cannulated selectively and the procedure was completed by an aortic root injection. We encountered two complications associated with catheterisation: one episode of transient myocardial ischaemia during injection of contrast medium in the main left coronary artery and one haematoma at the puncture site.

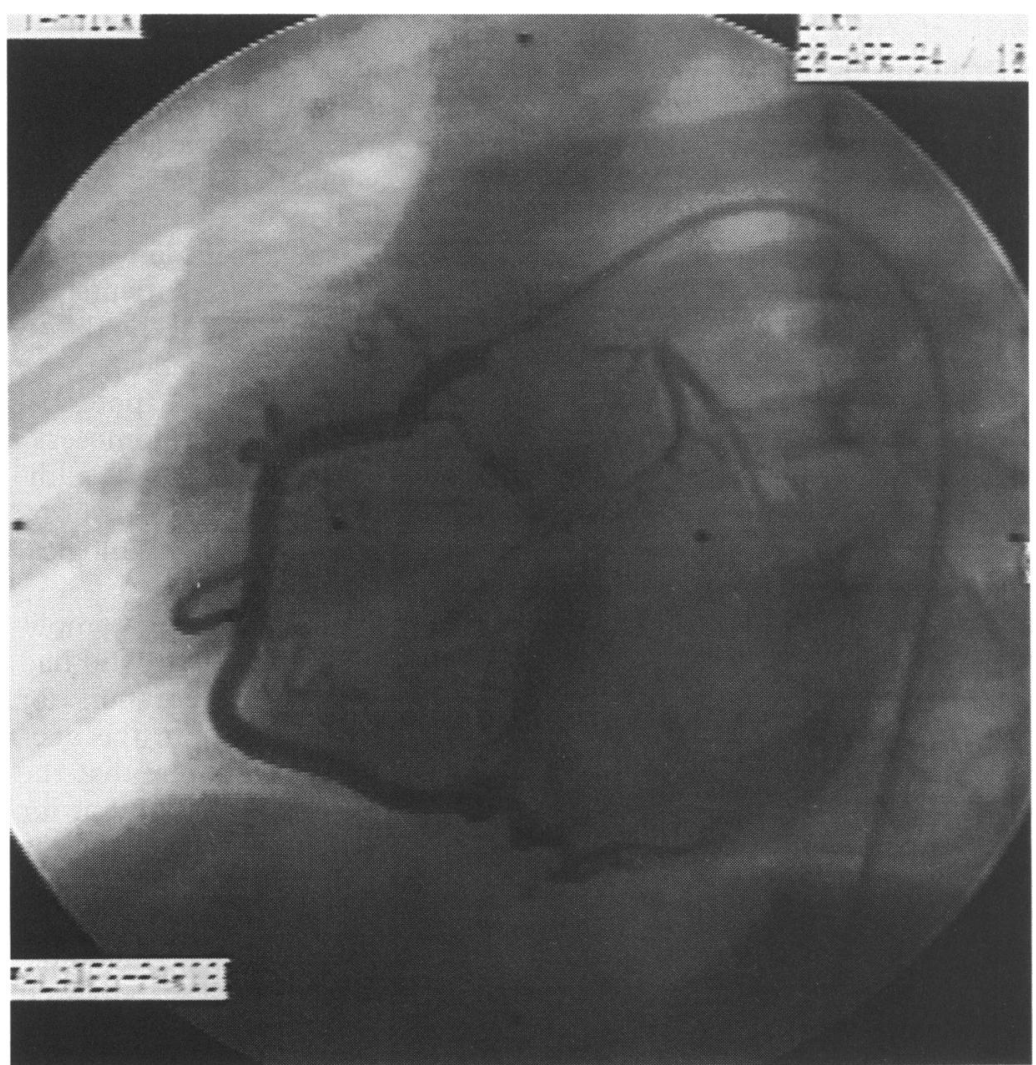

Figure 4 Occlusion of the left coronary artery ostium. Note the dilated right coronary artery and collateral vessels.
The anatomical pattern and ostia of the coronary artery could be imaged accurately in all patients. It was identical to surgical observation in all but two patients. In the first case, the surgeon described a normal coronary artery but the angiograms identified the three main coronary arteries arising from a single ostium and a second ostium giving rise to a conus branch. In the second case, the surgical findings were of a "single coronary artery" and the angiogram showed a single coronary artery with an isolated anterior conus branch arising from the pulmonary trunk.

Figures 1 to 3 show postoperative normal patterns of various types of translocated coronary arteries. Five patients had occlusion or stenosis of the coronary artery. Table 2 gives the clinical data and results of non-invasive evaluation in these patients. Three patients with "normal" coronary artery anatomy had obstruction of the left coronary trunk: one had complete occlusion with collateral vessels from the right coronary trunk (fig 4) and two had stenoses. Two patients with circumflex and right coronary arteries arising from right posterior facing sinus had occlusion of the circumflex artery. In the remaining 59 patients there was no evidence of obstruction of the main coronary artery. The right coronary artery trunk was free of stenosis in our series. The prevalence of late coronary artery complications in the 64 patients included in the study is $7 \cdot 8(95 \%$ CI 1.2 to $-14 \cdot 4 \%)$.

Table 3 lists the relations between functional status and coronary arteriography. A perioperative history suggestive of coronary artery complication did not predict late coronary artery stenoses. Each variable that we evaluated had a satisfactory predictive value for the absence of coronary lesions, but the positive predictive value of every item was poor. Nonetheless all three patients with occlusion of one of the three main coronary 
arteries had perioperative ischaemic complications, with associated ECG evidence of ischaemia or infarction and segmental left ventricular dysfunction with mitral valve insufficiency. Two patients with stenosis of the left main coronary artery trunk had no symptoms before catheterisation.

\section{Discussion}

This study describes a large series of patients having selective coronary angiography after anatomical repair for transposition of the great arteries. Because the outcome after the arterial switch operation varies considerably according to the experience of the centre, ${ }^{5}$ we studied consecutive survivors operated on by one surgeon and followed up by one hospital. We were interested in a reported series of sudden and unexpected late deaths related to occlusion of the coronary artery after the arterial switch operation. ${ }^{12}$ None of our patients died later than a year after surgery, but there is still uncertainty about whether the long-term patency of coronary arteries in survivors will allow them to lead a normal life without ischaemic events.

The considerable variability in the aortic origins and epicardial course of the coronary arteries in transposition of the great arteries has become the major technical limitation for arterial repair in newborns. ${ }^{17-20}$ On the basis of our experience, we used a revised classification of anatomical patterns (table 1). These three main patterns are closely related to the mechanisms of ischaemia after coronary transfer. ${ }^{15}$

We chose selective coronary angiography for various reasons. Firstly, it is extremely difficult to detect signs of myocardial ischaemia in infants. These patients have limited means of expressing their symptoms and myocardial infarction or sudden death may occur unexpectedly. ${ }^{12}$ Identification of inadequate coronary perfusion using myocardial scintigraphy has proved to be of uncertain clinical significance. ${ }^{1314}$ Moreover, perfusion defects are often seen in this category of patients and are usually related to the insult of open heart surgery rather than to coronary artery lesions. ${ }^{13}$ Secondly, although proximal occlusion of the coronary artery trunks can be shown by aortography, this technique may not be sufficient to display the detailed morphology of the coronary arteries. Finally, selective coronary angiography in children has become a very safe routine technique in our laboratory.

We found a relatively low prevalence of coronary artery obstruction $(7 \cdot 8 \%) 7 \cdot 6$ years after an arterial switch operation. The early postoperative results showed improvement with both the transfer of the coronary artery and reconstruction of the pulmonary artery. ${ }^{46}$ However, in our series, the occurrence of coronary artery lesions was independent of the surgical learning curve. A few patient-specific risk factors have been identified in patients with coronary artery anomalies. Although the anatomical pattern was a risk factor for early death in various series, ${ }^{10}$ it did not appear to be a risk factor for late coronary complications in our study. Perioperative ischaemic complications in isolation do not predict late sequelae. The significance of non-invasive findings, especially rest and exercise ECG anomalies, is not clear. In this study, we did not perform myocardial perfusion imaging. It is likely that this investigation could be a valuable adjunct in a group with structural abnormalities at the origin of the coronary arteries. ${ }^{21}$

Our findings strongly suggest that selective coronary angiography should be performed in children in whom the ECG and echocardiogram show evidence of myocardial ischaemia. In such patients we found occlusion of a major coronary artery and we assessed the anatomy of the collateral vessels. In both symptom free patients with left trunk stenosis we performed myocardial scintigraphy. In the first patient we found perfusion scan defects on thallium-201 SPECT imaging in the distribution of the left coronary artery whereas perfusion was normal in the second. Finally, using the ECG, echocardiogram, and adding myocardial scintigraphy we were, $a$ posteriori, able to predict coronary artery anomalies after arterial switch operation in four of our five cases.

Possible mechanisms of coronary artery occlusions after arterial switch operation include anatomical kinking, extrinsic compression, ${ }^{15}$ torsion, stretching, or fibrocellular intimal thickening. ${ }^{12}$ Although animal ${ }^{23}$ and human $^{24}$ studies have suggested that normal growth of the coronary-aortic anastomoses is likely to occur there is uncertainty about whether the translocation of the coronary arteries initiates an intimal proliferation that progresses gradually postoperatively.

A difficult question raised by our results is how should we treat these children with severe coronary artery lesions? Various surgical solutions might be considered, namely aortocoronary bypass or coronary artery trunk reimplantation. Dilatation of the main left ostium is probably dangerous in these patients. In view of the important limitations of the different treatments in very young children, we hope to be able to deal with the potential growth of the coronary-aortic anastomoses. ${ }^{22}$ In addition, progressive recruitment of additional collateral vessels may improve myocardial blood flow, at least under physiological conditions.

In conclusion, late coronary artery complications were uncommon in children who had undergone an arterial switch operation for transposition of the great arteries in the neonatal period. This supports our view that the arterial switch operation is best treatment for these patients. Preliminary analyses described in this study indicate that coronary artery patency could have been predicted with reasonable certainty by non-invasive methods. However, we believe that these children should be screened for late coronary artery lesions by selective coronary angiography, because coronary artery anomalies were found even in patients without symptoms. 
1 Castaneda AR, Norwood WI, Jonas RA, Colan SD, Sanders SP, Lang P. Transposition of the great arteries and intact ventricular septum: anatomical repair in the neonates. Ann Thorac Surg 1984;38:438-43.

2 Sidi D, Planché C, Kachaner J, Bruniaux J, Villain E, Le Bidois $\mathrm{J}$, et al. Anatomic correction of simple transposition of the great arteries in 50 neonates. Circulation 1987 75:429-35.

3 Bical O, Hazan E, Lecompte Y, Fermont L, Karam J, Jarreau MM, et al. Anatomic correction of transposition of the great arteries associated with ventricular septal defect: midterm results in $\mathbf{5 0}$ patients. Circulation 1984, 70:891-9.

4 Planché C, Bruniaux J, Lacour-Gayet F, Kachaner J, Binet JP, Sidi D, et al. Switch operation for transposition of the great arteries in neonates. $\mathcal{F}$ Thorac Cardiovasc Surg 1988; 96:354-63.

5 Kirklin JW, Blackstone EH, Tchervenkov CI, Castaneda AR, and the Congenital Heart Surgeons Society. Clinical outcomes after the arterial switch operation for transposioutcomes after the arterial switch operation for transposi-
tion: patients, support, procedural, and institutional risk tion: patients, support, procedural, a

6 Paillole C, Sidi D, Kachaner J, Planché C, Belot JP, Villain $\mathrm{E}$, et al. Fate of the pulmonary artery after anatomic correction of simple transposition of great arteries in newborn infants. Circulation 1988;78:870-6.

7 Jenkins KJ, Hanley FL, Colan SD, Mayer JE, Castaneda $A R$, Wernovsky G. Function of the anatomic pulmonary valve in the systemic circulation. Circulation 1991;84 (Suppl III):III-173-9.

8 Dae MW. Myocardial perfusion after repair of transposition: is it worth the switch? $\mathcal{F} \mathrm{Am}$ Coll Cardiol 1994 24:778-9.

9 Quaegebeur JM, Rohmer J, Ottenkamp J, Buis T, Kirklin JW, Blackstone EH, et al. The arterial switch experience: an eight-year experience. $\mathcal{F}$ Thorac Cardiovasc Surg 1986; 92:361-84.

10 Norwood WI, Dobell AR, Freed MD, Kirklin JW, Blackstone EH, and the Congenital Heart Surgeons Society. Intermediate results of the arterial switch repair: 20-institution study. 7 Thorac Cardiovasc Surg 1988;96: 854-63.

11 Mayer JE, Sanders SP, Jonas RA, Castaneda AR, Wernovsky G. Coronary artery pattern and outcome of arterial switch operation for transposition of the great arterial switch operation for transposition of the
arteries. Circulation 1990;82 (suppl IV):IV-139-45.

12 Tsuda E, Imatika M, Yagihara T, Ono Y, Echigo S, Takahashi $\mathrm{O}$, et al. Late death after arterial switch operation for transposition of the great arteries. Am Heart 7 1992;124:1551-7.
13 Hayes AM, Baker EJ, Kakadeker A, Parsons JM, Martin $\mathrm{RP}$, Radley-Smith R, et al. Influence of anatomic correction for transposition of the great arteries on myocardial perfusion: radionuclide imaging with technetium-99m 2methoxy isobutyl isonitrile. $f \mathrm{Am}$ Coll Cardiol 1994;24: 769-77.

14 Weindling SN, Wernovsky G, Colan SD, Parker JA, Boutin C, Mone SM, et al. Myocardial perfusion, function and exercise tolerance after the arterial switch operation. $f$ Am Coll Cardiol 1994;23:424-33.

15 Serraf A, Lacour-Gayet F, Bruniaux J, Touchot A, Losay J, Comas J, et al. Anatomic correction of transposition of the great arteries in neonates. $\mathcal{F} \mathrm{Am}$ Coll Cardiol 1993; 22:193-200.

16 Yacoub MH, Radley-Smith R. Anatomy of the coronary arteries in transposition of the great arteries and methods for their transfer in anatomic correction. Thorax 1978; for their tram

17 Kurosawa $H$, Imai $Y$, Kawada $M$. Coronary arterial anatomy in regard to the arterial switch procedure. anatomy in regard to the

18 Anderson RH. Description of the origins and epicardial course of the coronary arteries in complete transposition Cardiol Young 1991;1:11-12.

19 Day R, Laks H, Drinkwater DC. The influence of coronary anatomy on the arterial switch operation in neonates. $f$ Thorac Cardiovasc Surg 1992;104:706-12.

20 Gittenberg-de Groot AC, Sauer V, Oppenheimer-Dekker A, Quaegebeur J. Coronary arterial anatomy in transposition of the great arteries: a morphologic study. Pediatr Cardiol 1983;4(suppl I): 15-24.

21 Björkhem G, Evander E, White T, Lundström NR Myocardial scintigraphy with ${ }^{201}$ thallium in pediatric cardiology: a review of 52 cases. Pediatr Cardiol 1990 11:1-7.

22 Wernovsky G, Hougen TJ, Walsh EP, Sholler GF, Colan SD, Sanders SP, et al. Midterm results after the arterial switch operation for transposition of the great arteries with intact ventricular septum: clinical, hemodynamic, echocardiog a Circulation 1988;77:1333-44.

23 Brutel de la Riviere A, Quaegebeur JM, Hennis PJ, Brutel de la Riviere G, Huysmans HA, Brom AG. Growth of an aorto-coronary anastomosis: an experimental study in pigs. ₹ Thorac Cardiovasc Surg 1983;86:393-9.

24 Arensman FW, Sievers HH, Lang P, Radley-Smith $R$ Bernhard A, Heintzen P, et al. Assessment of coronary and aortic anastomoses after anatomic correction of transposition of the great arteries. $¥$ Thorac Cardiovasc transposition of the gr
Surg $1985 ; 90: 597-604$. 